\title{
A critical mathematics perspective on reading data visualizations: reimagining through reformatting, reframing, and renarrating
}

\author{
Laurie H. Rubel ${ }^{1}$ (D) Cynthia Nicol $^{2}$ (D) Anna Chronaki ${ }^{3,4}$ (D)
}

Accepted: 11 July 2021 / Published online: 14 October 2021

(C) The Author(s), under exclusive licence to Springer Nature B.V. 2021

\begin{abstract}
Data visualizations have proliferated throughout the COVID-19 pandemic to communicate information about the crisis and influence policy development and individual decision-making. In invoking exponential growth, mathematical modelling, statistical analysis, and the like, these data visualizations invite opportunities for mathematics teaching and learning. Yet data visualizations are social texts, authored from specific points of view, that narrate particular, and often consequential, stories. Their fundamental reliance on quantification and mathematics cements their social positioning as supposedly objective, reliable, and neutral. The reading of any data visualization demands unpacking the role of mathematics, including how data and variables have been formatted and how relationships are framed to narrate stories from particular points of view. We present an approach to a critical reading of data visualizations for the context of mathematics education that draws on three interrelated concepts: mathematical formatting (what gets quantified, measured, and how), framing (how variables are related and through what kind of data visualization), and narrating (which stories the data visualization tells, its potential impacts and limits). This approach to reading data visualisations includes a process of reimagining through reformatting, reframing and renarrating. We illustrate this approach and these three concepts using data visualizations published in the New York Times in 2020 about COVID-19. We offer a set of possible questions to guide a critical reading of data visualizations, beyond this set of examples.
\end{abstract}

Keywords COVID-19 · Data science education $\cdot$ Data visualizations $\cdot$ Critical mathematics education $\cdot$ Graph reading $\cdot$ Critical pedagogy

Laurie H. Rubel

LRubel@edu.haifa.ac.il

Extended author information available on the last page of the article 


\section{Introduction}

The coronavirus epidemic (COVID-19) began in late 2019 and spread rapidly around the globe. Governments, media, public health organizations, and the like produced, circulated, and relied on mathematics (e.g., statistics, calculus, modelling) to communicate about the pandemic and its myriad impacts, primarily in the form of data visualizations. Data visualizations about public health crises like COVID-19 could be generative for mathematics teaching, as suggested, for example, by Honnor (2020). Such a direction is further justified by how most people regularly consume data visualizations and, even if not consciously, contribute to their production (boyd \& Crawford, 2012). The increasing prevalence of data visualizations as a primary genre of crisis communication through mass media, however, raises issues of data trust, reliability, and ethics that demand problematizing any hasty classroom embrace. Our goal is to present an approach to reading data visualizations grounded in critical mathematics education and highlight its potential for classroom use.

We approach the social text of data visualizations (which we denote to include accompanying text and headline) from the vantage point of what Gal (2002) calls "reading contexts;" that is, reading data visualizations created by others, separate from (but connected to) authoring data visualizations. Prior research, across a range of disciplinary perspectives, explores how people come to read data visualizations (e.g., Börner et al., 2019; Galesic \& Garcia-Retamero, 2011; Glazer, 2011; Lee et al., 2016; Shah \& Hoeffner, 2002). Research in mathematics education elaborates how people learn to extract information from graphs and other representations, identify relationships and trends, make predictions, draw connections to broader contexts, question claims and data methodologies (Ainley, 1995; Ben Zvi \& Arcavi, 2001; Curcio, 1987; Friel et al., 2001; Shaughnessy, 2007; Watson, 1997; Watson \& Moritz, 1999). Current research has looked specifically at how people interpret data visualizations in the context of COVID-19 (e.g., Rotem \& Ayalon, 2021). For example, Romano et al. (2020) argue that the tendency to format COVID-19 data visualizations with logarithmic scales misled many and detrimentally impacted individual and public decision-making.

The authoring of a data visualization fundamentally relies on mathematics to produce a structure that highlights and defines quantities, relates variables, and justifies inferences. The grounding of data visualizations within this mathematizing process endows their produced narratives with an assumed authority, validity, and objectivity that, then, justify their mass consumption and circulation. Latour, in "The Pasteurisation of France," notes how mathematics played a role, for example, in creating social reforms against the battle of microbes of the late nineteenth century. These reforms introduced new norms around hygiene, vaccination, and medical infrastructure. As Latour (1984/1988) writes: "Without the creation of statistical bureaus and 'tableaux', without the application of political economy to this sociomedical problem, the 'difference in potential' would not have existed" (p.19). Latour's (1984/1988) argument is that Pasteur alone could not have inspired such tremendous change: it was the "tableaux" of numbers that convinced people to conform with new paradigms around healthy living (p. 19). Thus, then and now, mathematics plays a fundamental role in supporting narratives that ultimately shape our realities. For the COVID-19 crisis, these narratives addressed the effectiveness of various public health policies, the extent to which individuals obeyed directives, the impact on different population groups, and more. Often missing are stories about human (or nonhuman) actors, those about whom pertinent data are not being collected, and whose experiences are therefore not being valued or considered. 
Data visualizations are authored from specific vantage points. Shaughnessy (2007) named that in addition to being able to "critically read and evaluate information in tables, graphs, and media reports" it is important that people "adopt a healthy questioning attitude towards what is presented by sellers and buyers, by scientists and by the government, by politicians and by the news media" (p. 964). To this end, we elaborate an approach towards reading data visualizations that at its core surfaces and interrogates the role of mathematics. We begin by presenting three interrelated concepts to reading data visualizations: formatting, framing, and narrating. Then. we apply these concepts to a set of examples of data visualizations published by the New York Times (NYT). We demonstrate a critical reading of each example that culminates into potential reimaginings of the data visualization. We supplement this analysis with observations from three continents, from our local contexts of Canada, Israel, and Greece. ${ }^{1}$

\section{Critical reading of data visualizations for mathematics education}

We draw on ideas from critical mathematics education that explore how mathematics retains a double gesture by straddling both empowerment and disempowerment. That is, despite its aura of neutrality and objectivity, mathematics is widely used to reinforce social stratification (Frankenstein, 2012; Gutstein, 2006; Skovsmose, 2014). At the same time, mathematics potentially plays a supportive role in how people understand and respond to their and others' realities. Accomplishing the latter demands critique such as critical mathematics education which is connected to critical theory, critical race theory, feminist theory, critical statistics, and other theories that illuminate inequalities and foster activism towards justice. Critical mathematics education advocates interrogating constructed truths about the world produced by mathematical modelling, revealing hidden power structures that shape those constructed truths, reimagining and transforming those structures with mathematics to be more just, questioning the ethical and social pursuits of mathematization processes, and communicating critique and new possibilities to others (Frankenstein, 2012; Gutstein, 2006; Skovsmose, 1994, 2012).

There is a range of existing research in mathematics education about how people interpret what Friel et al. (2001) call "within context" (p. 138) graphs, those data visualizations that present data from real-world contexts. Existing research outlines developmental trajectories of graph reading abilities (Curcio, 1987; Friel et al., 2001; Shaughnessy, 2007), identifies common difficulties for learners (Bell \& Janvier, 1981; Lem et al., 2013), and outlines effective strategies for instruction (Shah \& Hoeffner, 2002; Watson, 1997). Across this work, the ability to interpret data visualizations is positioned as essential, not only for future professional success, but for individual decision-making and civic participation. However, data visualizations are typically treated as neutral, authoritative truths and interpretations typically do not engage the politics of representation (Chronaki \& Planas, 2018). A critical mathematics reading extends existing research about graph reading, beyond instrumental use of data visualizations or views of data visualizations purely as mathematical objects, to their role and production as social texts.

Data visualizations rely fundamentally on mathematics and are authored in response to specific conditions and contexts. We recognize that a process of reading data visualizations

\footnotetext{
${ }^{1}$ We write in English in a mixture of Canadian, British, and American English to accentuate diversity among our voices, and remind readers that English is privileged in academic discourse at the expense of other languages (see Meaney (2013); Phakeng (2017)).
} 
could benefit from pragmatics (Peirce, 1905/1998) or semiotics (Duval, 2006; Roth, 2002). Data visualizations structure the narrative process of a phenomenon by regulating, through particular elements and their combination, the representation of a problem and its tentative solutions (Neale, 1980). As social text, data visualizations represent particular arrangements of signs, cultural codes, ideologies, myths, stereotypes, along with quantified variables as an attempt to construct a picture of some aspect of the world. These representations are political in how, while seemingly providing a fixed image, they make certain aspects of a problem situation visible, while concealing others; downplay doubts and uncertainties; and limit presentation of possible alternatives. Some might approach data visualizations as fixed models of the world; not as products of an authoring process, but as singular representations of reality. Approaching data visualizations as social texts means, however, that they are neither fixed nor static, but culminate in the disruption of a discursive equilibrium until a new equilibrium is achieved (Todorov, 1977). As social texts, data visualizations cannot be taken at face value or assumed to be neutral carriers of information.

\section{Dimensions of critical reading of data visualizations for mathematics education}

\subsection{Formatting}

Mathematical formatting involves using mathematics to define and quantify towards describing some aspect of reality (Skovsmose, 1992). That is, people apply mathematics as a means of description, or "thinking abstractions" (Skovsmose, 1994, p. 51). Mathematical measures, systems, or models then become a compelling "image of reality" (p. 54). It is through "realised abstractions" (p. 52) that people then adapt reality to those mathematical systems or models, meaning that they format what is seen, known, or experienced, even though these models highlight or privilege only certain aspects of reality and overlook or oversimplify others. As a first example, consider the obesity index known as the body mass index (BMI, see Hall \& Barwell, 2015), by which a body's physical dimensions are quantified using a metric and then associated with a particular obesity index. The BMI relies on quantification of certain attributes of a person's body, one's mass and height, but ignores other relevant attributes, like bone density or muscle mass. Yet because it is compact, quantitative, and seemingly objective, BMI is readily used by insurance companies and others as inputs for risk models, even though it is an accurate description of obesity only for some bodies. As a second example of mathematical formatting, consider $R$, a virus' reproduction number, which became the "totemic figure in the COVID-19 pandemic" (Adam, 2020, para. 2). $R$ is defined as the average number of people expected to become infected by a single infected person, with $R_{0}$ assuming that everyone is susceptible and $R_{t}$ accounting for immunity. These $R$ measures serve as compact indicators of the spread of the contagion. Yet this particular mathematical formatting does not account for aspects of the pandemic found to be meaningful to understand the virus's spread, like superspreaders or locality of clusters. In addition, $R$ values are not directly measurable, but rather are produced by mathematical models, themselves based on additional mathematical formattings of reality.

These examples depict how mathematical formatting is not merely descriptive and often holds great power; "It is not just that mathematics determines what we 'see' but also guides our actions in "what we do"" (Skovsmose, 1992, p. 6). The formatting power 


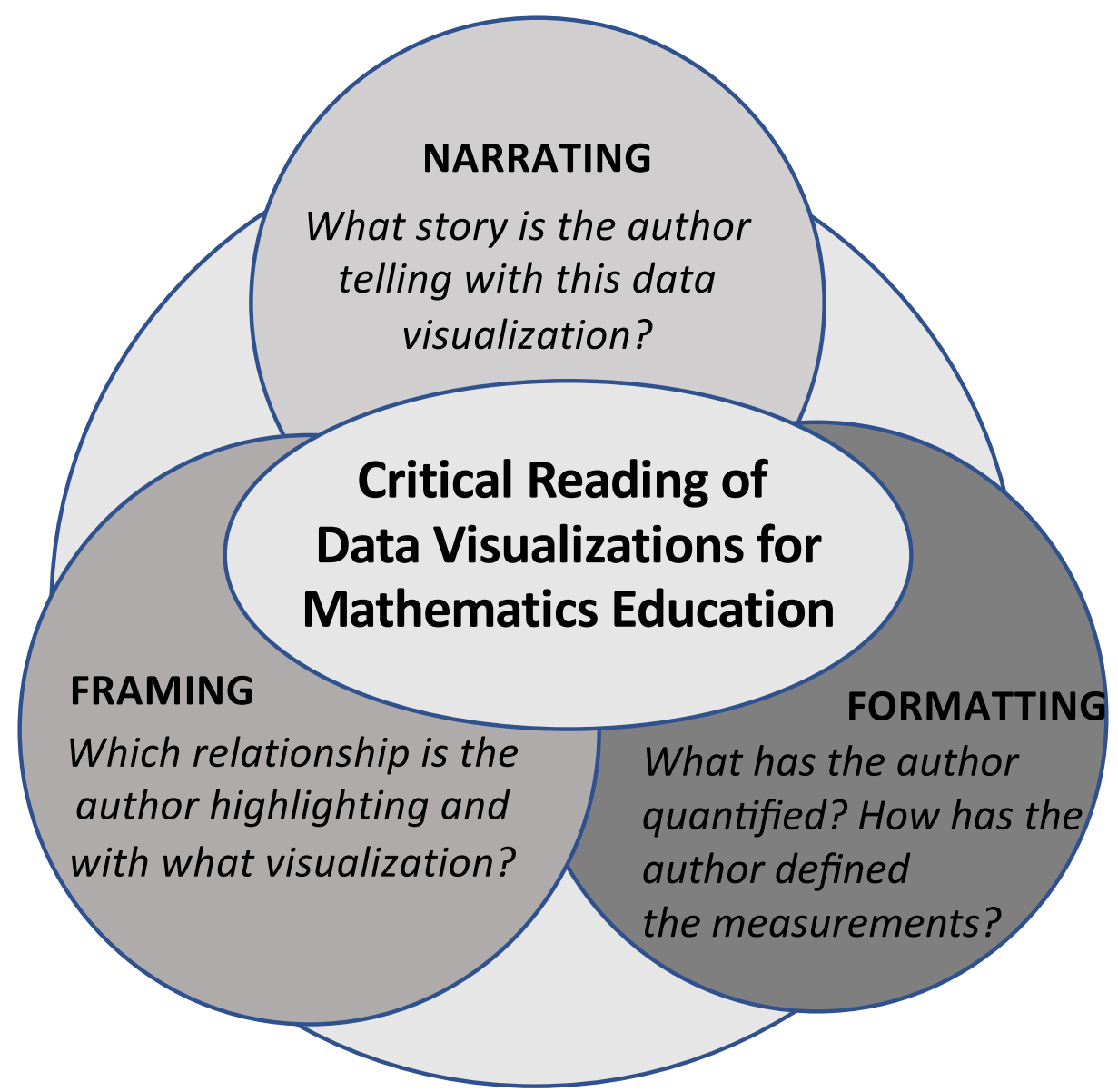

Fig. 1 Critical reading of data visualizations for mathematics education

of mathematics casts a guise of objectivity to what are partial interpretations, lends an implicit but authoritative voice, and enables an ease of communication. Although mathematical formatting can intimidate, violate, and even obscure, its role is usually protected and unnamed (Ewing, 2011). This creates, for mathematics, a "paradox of relevance" (Skovsmose, 1994, p. 82), of its pervasive social impact amidst a lack of recognition of such influence. As we show below and in Fig. 1, mathematical formatting embedded in data visualizations then sets the stage for the construction and communication of relationships through framing and narrating.

\subsection{Framing}

Framing signifies procedures of selecting and assembling certain elements at the expense of others (Entman, 2007) and results in a double process of inclusion and exclusion. As such, frames allow for the presentation of causality or relationship, and therefore can cast blame, honor, prompt, or justify particular solutions. Framing is significant because the frames "encourage target audiences to think, feel, and decide in a particular way" (Entman, 2007, 
p.164) and delineate what kinds of responses are seen as possible (Coburn, 2006). Our focus is on the framing of elements of data visualizations that have been mathematically formatted: meaning, the selection of variables; their relationship, for instance, by positioning one as independent or another as dependent; the choice of representation type as well as associated techniques (i.e., animation, zooming, and color) (Börner et al., 2019; Diakopoulos \& Hullman, 2011; Segel \& Heer, 2010). Data visualizations whose framing relies on geo-referenced data to show spatial relationships demand additional framing choices, like where the map will be centered, how it will be oriented, with which projection, how places will be named, and highlighting what kinds of borders. The framing of all of these mathematical elements is usually done implicitly, which then further amplifies its impact.

As an example of framing, consider this task posed by Tversky and Kahneman (1981), prefaced with a premonition that speaks directly to the COVID-19 crisis:

Imagine that the US is preparing for the outbreak of an unusual Asian disease, which is expected to kill 600 people. Two alternative programs to combat the disease have been proposed... If Program A is adopted, 200 people will be saved. If Program B is adopted, there is $1 / 3$ probability that 600 people will be saved, and $2 / 3$ probability that no people will be saved. Which of the two programs would you favor? (p.453)

This framing of Programs A and B is around potential gains, saving people. With this framing, most people preferred Program A over B, ostensibly because of preferring the guaranteed benefit rather than an option involving risk. However, Tversky and Kahneman (1981) posed a second version of this task to a second sample of participants, but around an alternative framing:

If Program C is adopted 400 people will die. If Program D is adopted there is $1 / 3$ probability that nobody will die, and $2 / 3$ probability that 600 people will die. Which of the two programs would you favor? (p. 453)

This time, instead of potential gains, the framing is around death and loss. In this second version, most people preferred Program D over the C, even though Program D implies a risk. Thus, the framing of death and loss led people to different decisions than the mathematically isomorphic framing of benefits and safety. This example demonstrates the potential significance of framing and how alternative framings might lead to alternate interpretations and decisions. Like with formatting, the framing process can be interrogated and deconstructed through a process of reframing, which we illustrate below.

\subsection{Narrating}

Framing is tightly connected with narrating the problem for the reader: In the previous example, the problem was narrated as a disease of an assumed Asian origin threatening US citizens. More generally, narratives tend to shape our understanding while sometimes serving to provoke new interpretations by problematizing the familiar. Yet narratives are far from neutral and become discursive material; dominant narratives hold authority related to certain historical moments (Hall, 1997). In some sense, one may view postmodernity as an effort to dismantle grand narratives and deconstruct them into local or meta-narratives. In the realm of COVID-19, grand narratives abound: how the virus spread, where, and at what rates; how these data relate with public health responses and their differential effectiveness; whose lives 
were lost or were otherwise impacted, where, and why; and more. In producing data visualizations, decisions related to mathematical formatting and framing are made within social, cultural, and political contexts and can indicate narratives of causality chains or that point to specific relationships. For example, narrating COVID-19 as a "Chinese virus" can be viewed in light of an historical pattern of the diminutive othering of the global East by the West (Scauso et al., 2020), evident in the earlier example. As constructed versions of reality, narrating is oftentimes done with intention, though not always explicitly, and can be told so compellingly that it is impossible to consider any other version in a kind of "narrative seduction" (Bruner, 1991, p. 9).

Mathematical formatting and framing organize structures for specific data interpretations and thereby prepare pathways for narration. The kinds of data that are available shape possible mathematical formatting and framings and the subsequent narratives that can emerge. "Data cannot speak for themselves" (Loukissas, 2019, p. 164), but instead are "sunk into narratives that give them shape and meaning" (p. 1) and woven into a process of "telling different stories for different purposes in different moments" (Dourish \& Gómez Cruz, 2018, p. 4). For example, Cohn et al. (2020) present framing alternatives for studying an outbreak, in terms of different mathematical formattings, such as cases per 1000 people, deaths per 1000 people, growth rates of infection over time, or growth rates by case count. Each different framing would then suggest alternate narratives, each of which, in turn, might demand a unique public response.

In some cases, data visualization's authors might seek to convey a specific narrative a priori and then select corresponding formatting and framing to support that narrative. For example, Narrative Science (narrativescience.com) is a corporation that offers clients socalled translations of COVID-19 large databases into story form, as designated by the client. For others, though, narrating or storytelling with data includes an ethical relationship that "articulate(s) forms of relevance and responsibility that might be activated through data" (Gabrys et al., 2016, p. 5). Gabrys and colleagues' project on air pollution presents an example of how democratic practices around data, like citizen sensing, narrate stories that might otherwise have gone untold, and in so doing, mobilize community responses and action.

\subsection{Towards reimagining our relation to data visualizations}

A critical reading of data visualizations for mathematics education prompts a process of reflection about what these data might tell, to whom, and why, as depicted in Fig. 2. That is, questioning, interrogating, and troubling a data visualization's mathematical formatting, framing, and narrating can make its boundaries visible. A critical reading of a data visualization's mathematical formatting suggests reformatting the captured reality in new directions, perhaps by considering other measures or kinds of experiences that have not yet been captured with data. A critical reading of mathematical framing poses questions as to how frames might be reconstituted, transformed, and thereby reframed, by considering alternatives to how variables are being related or how relationships are being represented. Finally, a critical reading of a data visualization's narrative leads towards renarrating, to expand which stories are being told, and thereby whose voices and experiences are being heard. In sum, through reformatting, reframing, and renarrating, a critical mathematics reading of a data visualization prompts its reimagining, towards a more complete and deeper understanding of the situation at hand. 


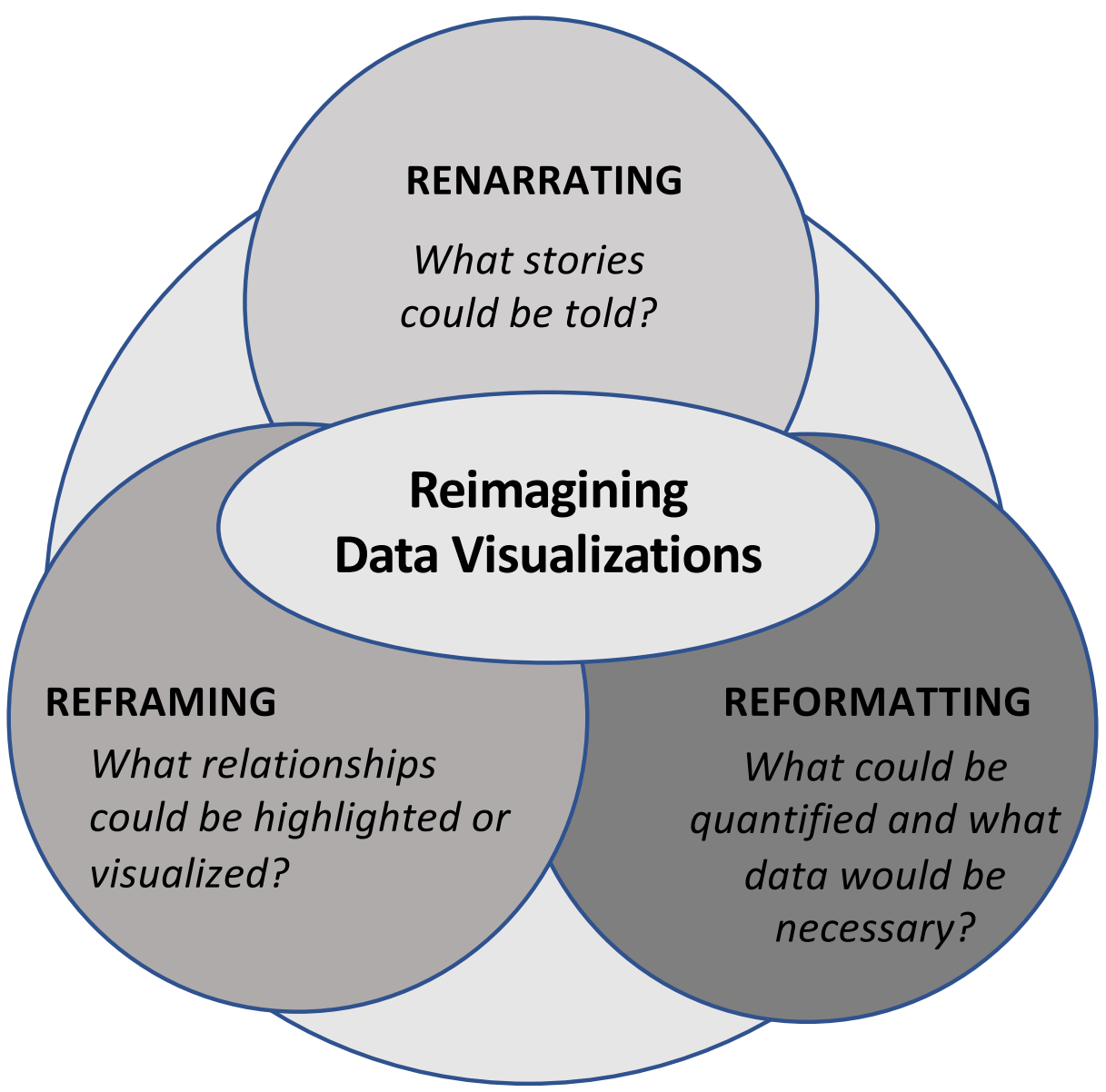

Fig. 2 Reimagining data visualizations by reformatting, reframing, renarrating

\section{Critical reading of data visualizations: examples from the COVID-19 crisis}

In this section, we enact a critical mathematics reading of four examples of data visualizations published in the NYT between March 25 and May 27, 2020, about COVID-19 (see Table 1). These dates represent the beginning of the global impact of the virus and resultant crisis. We chose the NYT as a media source primarily because of its frequent production of interactive data visualizations but also because of its global voice. The vantage point of the NYT is a particular city seen to be cosmopolitan, yet rife with contradictions: multicultural yet racially segregated; culturally avant garde yet home to extreme income inequality; and most important here, a media leader yet early hot-spot for COVID-19. We emphasize, though, that readers can use this process relative to other data visualization. We chose this particular quartet of examples because of how each highlights different dimensions among formatting, framing, and narrating and the role of mathematics therein.

For each example, we identify and interrogate its interrelated processes of mathematical formatting, framing, and narrating and prompt potential directions for reimagining. We 


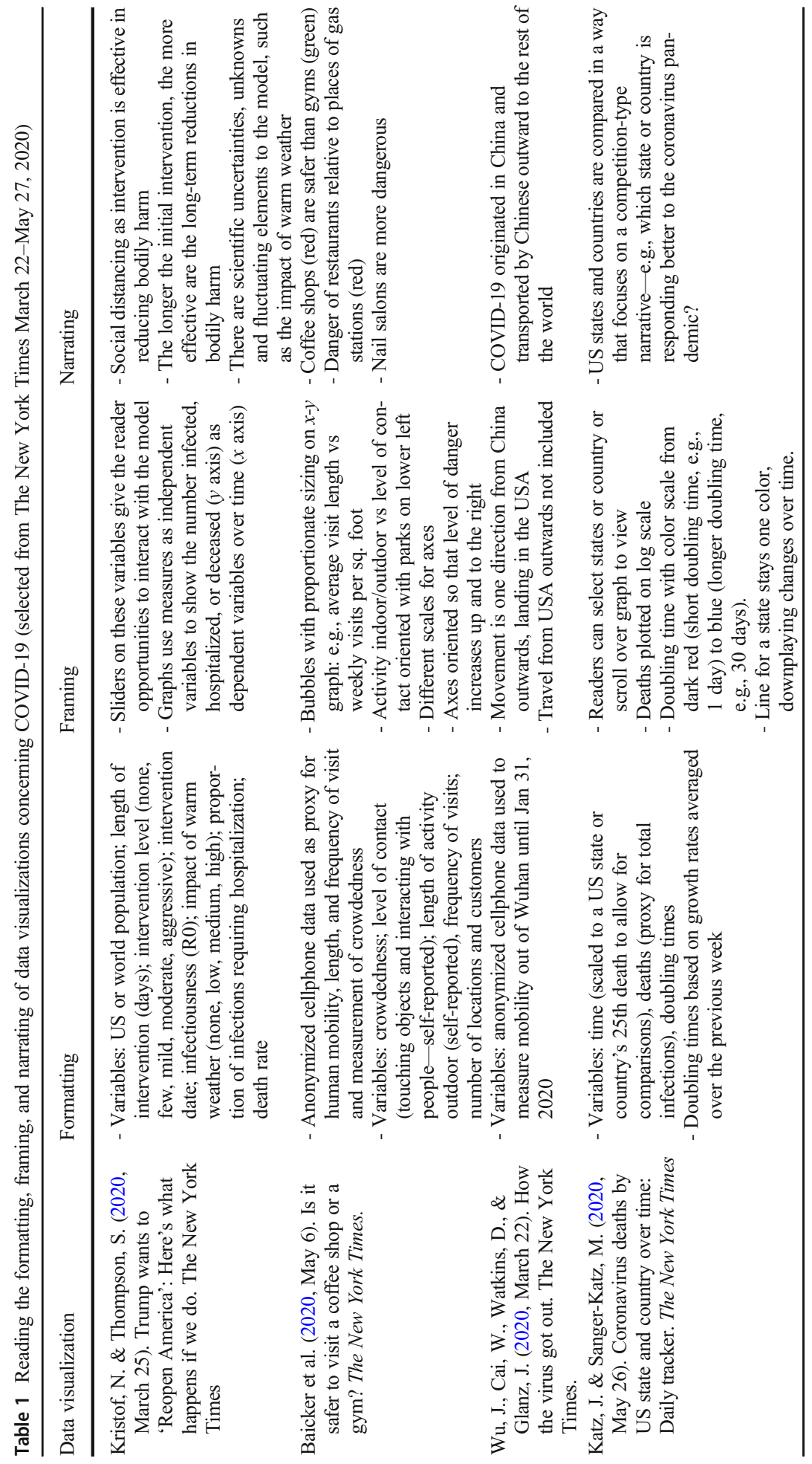


contextualize our critical reading of each data visualization with respect to observations from the authors' local contexts, oftentimes outside the bounds of the prevalent global narratives, and usually overlooked by US-focused or other wide-lens views. Our stories are derived from local media, ground-truthing information from others, and alternative media sources not readily accessible through online English journalism. We focus on elements that, even at the scale of these countries, might not be centered for public attention. In so doing, we complicate any simplistic views of data visualizations as universal and immaterial. Instead, we emphasize how place, as the context in which data are created, gathered, managed, shaped, displayed, and shared, encompasses social and spatial elements that determine how we interpret or experience data visualizations (Loukissas, 2019).

\subsection{Example 1: Data visualizations conceal fundamental inequalities}

Our first example, published early in the initial US outbreak, is Kristof and Thompson's (2020) data visualization titled 'Trump Wants to 'Reopen America': Here's What Happens if We Do." We selected this interactive data visualization because of how it makes specific mathematically formatted variables explicit, like duration of social distancing (in days), start date, level of infectiousness (using $R$ ), and impact of warm weather (using categorical variable). The data visualization's framing offers sliders for the reader to explore, that can change the values of each specific variable to produce a graph that projects outcomes. In this case, the framing of this data visualization relates those independent variables to certain aspects of the human toll, namely numbers of "infected," "hospitalized," or "deceased." The use of sliders as part of this framing allows readers to manipulate these, but only these, variables, across a predetermined range of values. This data visualization yields a narrative that early social distancing interventions at the time of the initial outbreak in the USA would have saved more lives.

Several key assumptions, however, remain implicit; in this case, that interventions would impact people evenly, that lives are fought to be preserved with the same number of resources and amount of intensity, and that the virus is indiscriminate in its infection. However, bodily outcomes of these distinctions were readily apparent worldwide (Scauso et al., 2020). Kristof and Thompson's model does not depict the pandemic's uneven impact and does not make these patterns visible. For example, this data visualization makes no distinction about the disproportionate impact of COVID-19 on women, in terms of unemployment, risks of domestic violence, and added cognitive labor produced by locating work and school in people's homes (Calarco et al., 2020). When data are gathered in contexts in which major power imbalances prevail, uneven results can be expected (D'Ignazio \& Klein, 2020). A critical reading of Kristof and Thompson's (2020) data visualization demands reimagining to take various kinds of unevenness into account. Reimagining could pay attention to race, gender, and other social variables, as they carry meaning in local contexts. We amplify the need to reimagine data visualizations that better represent COVID's impact and toll, from two of the authors' contexts, Canada and Greece.

Ongoing colonizing narratives along with intergenerational trauma position Indigenous communities in Canada as vulnerable to COVID-19. Historically, Indigenous communities across Canada have experienced waves of infectious diseases since European settlers arrived in the country. Past epidemics were devastating to once thriving Indigenous communities, decimating, in some cases, entire villages. Canada's colonial history narrates this devastation as Indigenous peoples lacking physiological immunity. A preferred alternative, instead, identifies governmental decisions and actions with colonial logics as creating conditions for 
vulnerability to disease. The forces and structures of colonialism continue today. With respect to COVID-19, for example, recommendations around social distancing assume access to space, a challenge when forced to live in overcrowded housing, a common difficulty on First Nations reserves (Statistics Canada, 2017). Furthermore, work and schooling at home in isolation require stable internet, affordable cellphone data plans, and credit cards for online purchasing. While Canada's land area initially helped to curb the spread of COVID-19 among rural and remote communities, later, this vast geography further accentuated increased vulnerability for Indigenous peoples. Isolated areas have fewer medical resources and less access to hospitals. Frequent hand-washing presumes access to an abundance of clean water, impossible for many communities who live under boil-water advisories (Lukawiecki, 2018). Furthermore, despite this added vulnerability, reports from Canada's health authorities suggest an undercounting of the toll on First Nations communities, because these authorities do not track or report who is Indigenous (Cardinal, 2020). Without more complete information, Indigenous communities will continue to struggle to make and evaluate decisions within and across levels of self-determined health administration and governance (Skye, 2020).

Roma people (about 2 to $3 \%$ of Greece's population) are often integrated in Greece's urbanscape, but many live with extended families in ghettoized neighborhoods and some work as merchants in open markets (Chronaki, 2011). In the initial COVID-19 outbreak, in response to an outbreak among Roma people in a single neighborhood, the government ordered a complete, month-long lockdown of that area's open markets around the usually busy Easter holiday (Ta Nea, 2020b). This act surfaced tense preexisting narratives related to culture and norms of social hygiene that stigmatize Roma people. Roma neighborhoods were targeted with more stringent lockdown and intervention measures, to the extent of requests that entire Roma communities be tested, or that people be placed pre-emptively in quarantine. Along with the impact of increased racialization, this period exacerbated financial problems not only for Roma people, who could not work, but for many low-income people who rely on affordable markets to meet their basic needs. Stories like the ones we have presented here about the Roma of Greece and Indigenous peoples of Canada are not visible in pervasive data visualizations like Kristof and Thompson's (2020). Reimaginings that value local stories like these likely demand alternative formattings, with the gathering of data that until now has not been collected or new kinds of quantifications, assembled and related through new framings to narrate new stories.

\subsection{Example 2: New narratives demand new mathematics}

We provide as a second example Baicker et al.'s (2020) data visualization titled "Is it Safer to Visit a Coffee Shop or a Gym?" We selected this example because it employs non-traditional mathematical formatting and framing and thereby highlights those dimensions of a critical reading. This data visualization was produced at a time of decision-making by governments and individuals about which businesses might be safe to reopen or to visit. Baicker et al. formatted new variables to quantify a business's popularity relative to its physical crowdedness (weekly visits per square foot) and average time length that people spend there per visit. Baicker et al. then framed their data visualization by relating these variables in particular ways, in this case by framing the popularity with respect to crowdedness as the independent variable and the average visit length as the dependent variable. The data visualization accounts for businesses having more locations and more customers through proportionate sizing the data visualization's circles representing each business. This formatting and framing produces a narrative that restaurants and bars, as well as gyms, are particularly dangerous, mostly because of their longer average visit lengths. 
In the accompanying text, Baicker et al. explain that such a framing overlooks the level of physical interaction between people and how much of that interaction occurs indoors, both understood to be significant with respect to COVID-19. They present a second data visualization accounting for this additional formatting - illustrating the potentiality of reformatting and reframing - that ultimately highlights how gyms and nail salons seem particularly dangerous for contagion (see Fig. 3). Yet the narrative produced by this and similar data visualizations is that a society's "re-opening" pertains to businesses, and that certain businesses are categorically safer than others. Limiting our thinking about "re-opening" to businesses ignores questions about other kinds of potentially important re-openings. Reframing this particular data visualization could support alternative narratives, perhaps around which places are safest, like parks, rather than which pose the most dangers, through a reversed orientation of the axes. Reimagining could tell us which public spaces contribute to people's physical or spiritual well-being; how safe businesses are for their employees, rather than only its customers; which places are more consequential for children and their needs; and which spaces might be significant for social practices of marginalized groups.

To illustrate the need for these kinds of reimaginings, we bring a further example, this time from Israel, another of the authors' local contexts. Israel's ultra-Orthodox Jewish ("Haredim") form about $22 \%$ of its population. This minority group was vulnerable to COVID-19 in many ways, because of similar kinds of factors that produced added vulnerability for Indigenous peoples in Canada and Roma people in Greece, discussed in the previous example. Haredim are perhaps uniquely marginalized among this set in how they abstain from the internet and secular media. Furthermore, their vulnerability to viral infections is produced by the communal

\section{$\uparrow$ Activity indoors}

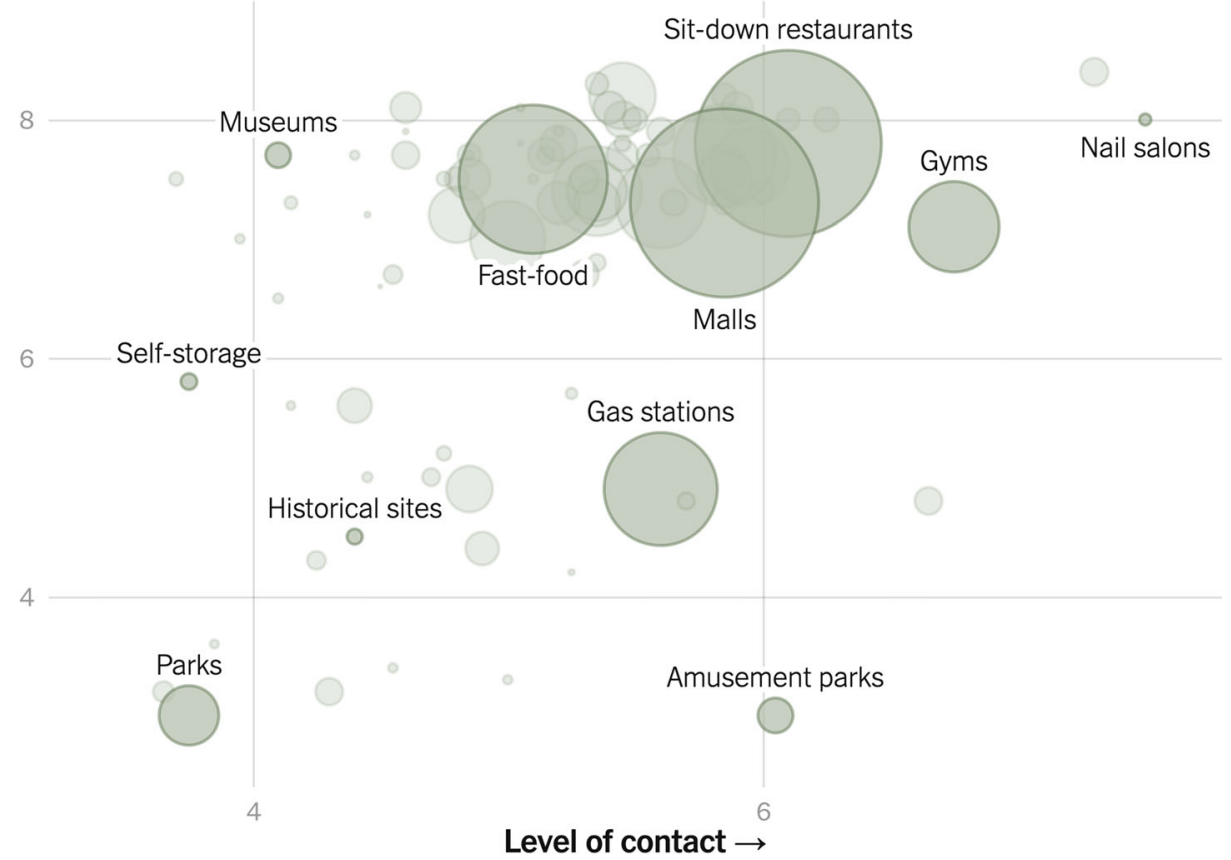

Fig. 3 Degree of indoor activity and level of contact/interaction for different spaces (Baicker et al., (C) 2020 The New York Times Company) 
nature of their daily, intensive group-based prayer practices that require group quorums. Burial, holiday-observance, and wedding practices are communal and involve religious rituals that Haredim might not view as optional, like shopping or entertainment might be to others. A critical reading of Baicker et al.'s data visualization, and others like it, prompts for reimaginings that consider social practices more broadly than retail businesses. A failure to consider social practices of a society's minor and marginal groups, as in this example, sidesteps questions of safety and wellness for these people and exacerbates their alreadyexisting vulnerability.

\subsection{Example 3: Formatting mobility and infection}

As a third example, we look to Wu et al. (2020), who produced "How the Virus Got Out," a data visualization that narrates the initial spread of the virus beginning in December 2019. We selected this example because, different from the other examples, it relies on a mathematical formatting of mobility, place, and time. This data visualization relies on a mathematical formatting of mobility using a proxy of cellphone movement data, which implies that the mobility of certain segments of the population is not included in the dataset. In our local contexts, formatting mobility in terms of cellphone data, and basing decision-making or contact-tracing on that formatting neglects specific groups of people: in Israel, Haredim, because they typically do not use smartphones and in Canada or Greece, those in remote or rural areas who have scarce cell network access. Across all contexts, these data visualizations do not include children or low-income people without cellphones.

$\mathrm{Wu}$ et al.'s dynamic data visualization frames space and time at various scales: in animation, it begins with a centering on China, zooms in to Wuhan, zooms back out, and further outward to connections to other cities around the world, all the while framing density of movement from Wuhan outwards. The data visualization culminates with a map view of the USA and its subsequent spread there. This data visualization yields a narrative that critiques slow decisions about travel restrictions by the Chinese and later the US governments. Yet $\mathrm{Wu}$ et al. (2020) frame mobility and virus contagion only in a unidirectional path, from China outwards. This framing then produces a narrative which blames the pandemic on people from China, which easily melds with existing colonial logics that already frame the relationship between the global East and West. A reframing would recognize that mobility, and likewise contagion, are multi-directional. Such reimaginings support other kinds of narratives, including that the mobility of infected people from and within the USA and other countries was a major driver in transforming the virus to a global pandemic (e.g., Chuang, 2020).

Narratives of directionality of infection are significant at community, national, and international scales. As an example, consider the 66-year-old Greek Orthodox man who had recently returned from a pilgrimage to Jerusalem, a journey taken on the heels of his surviving a heart attack, among the first reported COVID-19 deaths in Greece (Ta Nea, 2020a). Upon return, the man, known in Greece as "case number 9," was hospitalized for COVID-19 and unfortunately did not survive. The Greek media attributed the source of this man's infection to his pilgrimage to Israel (Ta Nea, 2020a). At the same time, this "Greek tourist group" of which this man was a part was also infamous in Israel, being positioned as having brought the virus to Israel from Greece. The tour's local bus driver, a Palestinian resident of East Jerusalem, was known as Israel's "patient number 16." Because he was in serious condition at the time of still zero fatalities in Israel, he was prominent in the Israeli local media at the outbreak's start (see Israel Ministry of Health, 2020). Whether the virus passed from people in Greece to Israel, or vice versa, is 
ultimately irrelevant to the virus' global spread, but this example shows that these narratives bear significance with respect to blame, responsibility, and even international relations.

\subsection{Example 4: International comparisons and what is lost in aggregation}

We conclude with the example of Katz and Sanger-Katz's (2020) data visualization an international comparison that ranks countries according to numbers of COVID-19 deaths (see Fig. 4). We selected this example because its framing and formatting here are mathematically complex, with a graph that uses a logarithmic scale and representations that depict changes in doubling time by country over time for "total deaths." The data visualization presents a trendline that shows each country's total number of deaths and the doubling time of that variable. Differences in mathematical formatting from country to country-in terms of what is counted and how - muddle this kind of international comparison, making it difficult to interpret individual data points without knowing more about those contexts. For instance, although numbers of deaths are a significant dimension of the crisis, it is not equivalent to the virus' spread or impact. Other variables could illuminate how other differences between countries likely contribute to creating the visual patterns in this graph.

The primary narrative that emerges from this data visualization is that the numbers of deaths were growing fastest in the USA as of June 1, 2020. After that date, likely because this framing does not lend itself to such an extended timeline, the NYT shifted to a new data visualization for international comparisons (see New York Times, 2020), explaining that the previous was "no longer as useful." The newer data visualization continues to present an international comparative perspective but now relies on a formatting of normalizing "weekly cases per capita" as well as "total deaths" but this time per capita using an array of representational techniques: global heat maps, heat charts, and side-by-side graphs of individual countries that show changes in these measures over time. The newer framings produce various kinds of

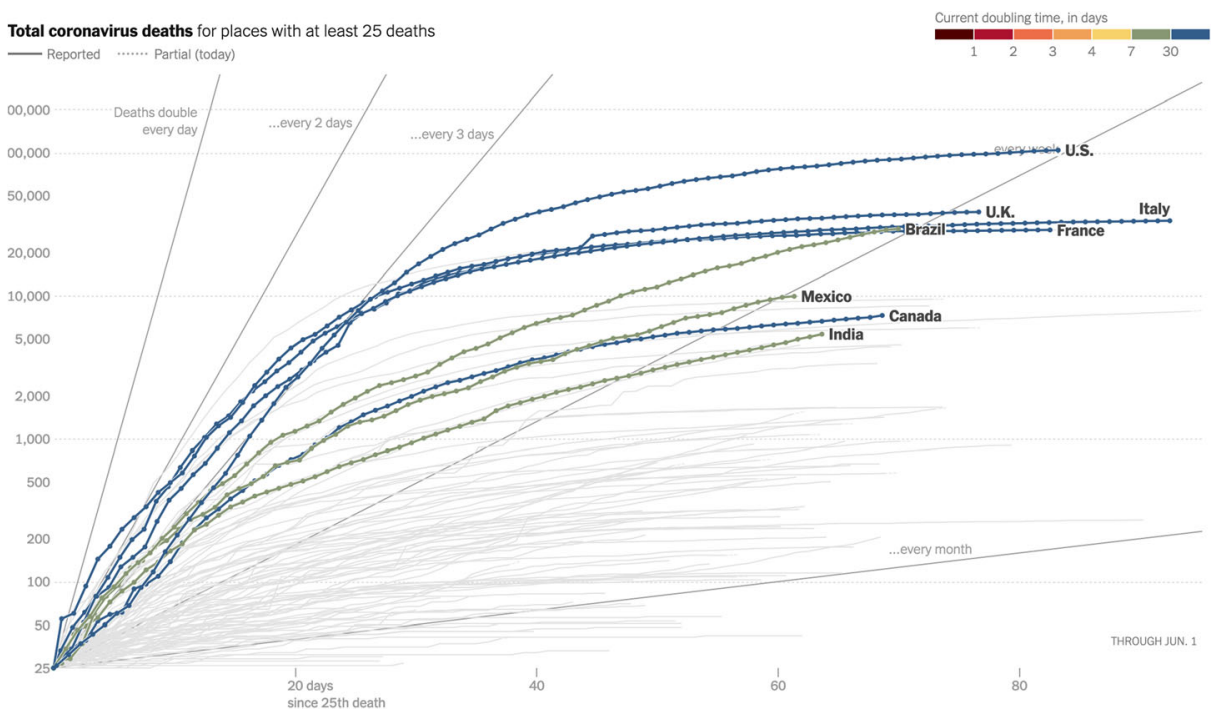

Fig. 4 Total coronavirus deaths over time as of June 2020 (Katz \& Sanger-Katz, (C) 2020 The New York Times Company) 
international rankings, according to deaths or cases per capita (which are not equivalent) and groups countries in terms of their numbers of new cases per capita.

Comparative framings tend to promote narratives of competition that accentuate a perception of a scarcity of resources rather than cooperation and solidarity. Moreover, these aggregate framings do not make patterns of injustices visible and detract from an emphasis on inequalities happening within places. For example, data visualizations framed around international comparisons, like those highlighted here, depict winners and losers, might suggest that some countries have responded better than others or that some have more disciplined citizens than others. There are, of course, other ways of interpreting these distinctions, by looking more closely at local places, to find a reality woven in discourses of race, gender, class, and religions, for example, as we have described above. In general, we challenge the tendency towards framings that compare groups, cities or countries, largely because of a lack of consideration of each local context. Yielding to the pressure of producing global comparisons, this pervasive framing quickly dissolves the local and the ways in which this crisis has unfolded differently by context.

\section{Discussion and implications}

This paper argues for the need to turn towards a critical reading of data visualizations as social texts, by considering how data visualizations mathematize reality through interrelated processes of formatting, framing, and narrating. We have selected particular examples specific to the global COVID-19 crisis and contextualized our discussion about the need for reconfigurations relative to examples from our local country experiences. Through these examples we have illustrated critical readings of data visualizations through formatting, framing, and narrating (summarized in Table 1). Reading data visualizations with this orientation, we have argued, reveals how data visualizations rely on mathematics, play a significant role in shaping local and global decision-making, but are not neutral representations.

In examining the role of mathematics in society, Skovsmose (1994) describes different types of knowing: mathematical, technological, and reflective knowing. While any reading of data visualizations engages mathematical and technological knowing, reflective knowing demands a critical reading. Reflective knowing is key for questioning the role of mathematics in the decision-making process of creating data visualizations, including the assumptions and choices that were made, those embedded uncertainties, and intended or unintended consequences of the mathematization process. The approach to critical reading of data visualizations offered in this paper provides a strategy for reflecting on data visualizations through reimagining, outside of and beyond this particular crisis. The processes of formatting, framing, and narrating are interactive in the ways they shape each other as well as understandings of the current pandemic or any other crisis. It is such reformatting, reframing, or renarrating of data visualizations that could involve us in what Skovsmose (2018) refers to as "hypothetical reasoning," that is, in this case, asking active questions that lead to reimagining the data visualization.

Our presentation of a critical reading of data visualizations about the COVID-19 pandemic reminds us of the varied nature of data - of its seemingly universal status and at the same time its localness (Loukissas, 2019). Stories from our local contexts call attention, in particular, to so-called missing datasets, absent for a range of reasons: a perceived difficulty of quantification or measurability, local, nuanced narratives are less valued because of their inherent 
specificity, or because their absence supports financial interests of dominant groups. Aspects of reality that might be challenging or even impossible to mathematically format fall out of bounds of the framing and narrating and, therefore, are out of bounds of a reality that cannot be perceived in other terms. Naming these "blank spots that exist in spaces that are otherwise data-saturated" (Onuoha, n.d.) is crucial because doing so allows for identification of borders of knowledge or, even, what society is willing to know. Gathering and sharing stories that might otherwise be missing, in and across contexts, problematize what is typically or historically valued as privileged knowledge and challenge that which is marginalized or ignored. A critical reading of data visualizations that includes local stories provides insight into how data visualizations are shaped by context and history, place and people, institutions and businesses. This process challenges the prevailing myth in mathematics education of producing fixed and certain knowledge through the process of data visualization.

Following Skovsmose (2018) we ask, "How can we construct classroom activities that, on the one hand, acknowledge the complex mathematization of social practices and, on the other hand, acknowledge the profound demathematization of such practices?" (p. 608). We see a number of implications for mathematics classrooms of critical readings of data visualizations. In Table 2, we present questions that could guide a process of critical reading for the

Table 2 Reimagining: questions for a critical reading of data visualizations for mathematics education

Reimagining Questions

Reformatting - What is (and what is not) measured and counted? What data proxies are used (e.g., cell phone movement used as a measure of human mobility, purchasing data, social media behavior, open data, personal stories)? What other data could be collected? What data are missing? What obstacles might there be to gathering these data?

- How are measurements defined and how are these data generated? How explicit is the underlying formatting within the data visualization (e.g., is it clear or obscured)?

- Who gathered these data? Who is asking the questions about whom? Who "owns" these data, and who might profit from these data? Who has access to these data (are data drawn from an open source)?

- When and where were these data collected?

- Why were these data collected and used in this data visualization, and how do you know?

Reframing - What kind of graph or visualization is used? What do the axes represent? How are the axes scaled and oriented? What other dimensions could be used to explore these measures? What connections or relationships are promoted or emphasized by this framing? What blind spots does this framing create? What other ways might these measures be framed?

- How are the data situated or contextualized? If a map, where is it centered, how is it oriented, and how are boundaries determined? How does this framing produce particular narratives?

- Who authored this particular framing and for whose interests? (e.g., academic, government, business, community group)

- When and where (in what historical and

geographical contexts) does this particular framing apply?

- Why are these relationships framed in this way?

Renarrating - What narratives are being told through the data visualization? What other narratives might be told through these data or this framing? What narratives are unintentionally told, or not told through this data visualization? What consequences or actions might be possible through this narrative and what might be their effects?

- How do the authors operationalize the data through the narrative (e.g., is narrating done through additional text)? How does the narrative give insight to the data settings or local contexts? How does the communicated narrative reinforce (or challenge) existing power relations?

- Who benefits from this way of narrating the data visualization, when, where, and in what ways?

- How does this narrative make you feel? How might it prompt you to action and in what directions? 
classroom, by unfolding and unpacking a data visualization in terms of its formatting, framing, and narrating. These questions prompt interpretation of choices made by the authors of the data visualization, and some might be difficult to answer. More generally, the process of reimagining - how the data visualization could be reformatted, reframed, and, ultimately, renarrated - is a way to deepen understanding of the situation at hand and acknowledge limitations of our knowledge. Many questions, for example, make clear the need to attend to missing data. Teachers could prompt students more specifically to consider a data visualization in terms of how its particular formatting has aggregated experiences in ways that might be problematic and to suggest reformattings that might be more inclusive or lead to more representative results. Alternatively, teachers could prompt students to consider a data visualization in terms of how its framing of data invites specific narratives and to explore how reframing (e.g., relating variables differently, employing other visualization techniques) might suggest alternative narratives. By asking and answering questions like those in Table 2, students explore how a data visualization's interrelated formatting, framing, and narrating might resonate with privileged perspectives, uphold certain hierarchies of power, perpetuate particular values over others, and guide towards certain decisions.

The unpacking of the essentializing globality of the data visualizations in the New York Times with our local experiences creates an opening in terms of how we envision that our proposed approach to reading data visualizations might reach classrooms, with more of a focus on the local. Appreciating the power of data visualizations through a critical process that involves reformatting, reframing, and renarrating may inspire students to author data visualizations from their own vantage points. Such authoring could involve students in decisionmaking around what data should be collected, quantified, and measured; possible or desired framing possibilities; and how they could/should narrate patterns produced by such framings. That is, critical readings of data visualizations might further inspire civic journalism efforts, whereby local community organizers, activists, students, teachers, and interested citizens research their own localities, create or author data visualizations, and thus format, frame, and narrate data visualizations - their truths - in ways that would generate a different sort of problem visualization. Critical authorings of data visualizations, together with critical readings of data visualizations, will potentially make visible possibilities and limitations of data visualizations from mathematical, ethical, technological, and political perspectives. Of course, research that studies how this proposed approach supports (or limits) learning in these directions is needed. In addition, we are curious as to how educators from outside of mathematics education, like social studies or other sciences, might adapt this approach to critical reading of data visualizations in the context of their disciplines.

We emphasize that teaching students processes like "notice and wonder" (Burton, 1984, p. 46) are not sufficient. Notice and wonder is an important first step but needs to be expanded to include "feel" - about narratives produced by said data visualization, about inequalities represented therein, and about ways in which a data visualization ignores or marginalizes some perspectives and people - as well as "act" - what someone might do in response to those feelings, noticings, or wonderings. Mathematics teachers and teacher educators, who might be accustomed to engaging with data visualizations as mathematical objects rather than social texts, are likely to experience dilemmas in this regard. When teachers and teacher educators approach data visualizations as instrumental tools to teach certain mathematical ideas or techniques, they might ignore or downplay reading data visualizations in terms of their formatting, framing, and narrating and how those intersect with power. We advocate for approaching data visualizations as social texts and to create deliberate space for considering power relations relative to ethical responsibilities. 


\section{References}

Adam, D. (2020). A guide to R - the pandemic's misunderstood metric. Nature. Retrieved July 15, 2020, from https://www.nature.com/articles/d41586-020-02009-w

Ainley, J. (1995). Re-viewing graphing: Traditional and intuitive approaches. For the Learning of Mathematics, 15(2), 10-16.

Baicker, K., Dube, O., Mullainathan, S., Pope, D., \& Wezerek, G. (2020, May 6). Is it safer to visit a coffee shop or a gym? The New York Times. Retrieved May 13, 2020, from https://www.nytimes.com/interactive/2020/ 05/06/opinion/coronavirus-us-reopen.html

Bell, A., \& Janvier, C. (1981). The interpretation of graphs representing situations. For the Learning of Mathematics, 2(1), 34-42. https://www.jstor.org/stable/40240746

Ben Zvi, D., \& Arcavi, A. (2001). Junior high school students' construction of global views of data and data representations. Educational Studies in Mathematics, 45, 35-65. https://doi.org/10.1023/A:1013809201228

Börner, K., Bueckle, A., \& Ginda, M. (2019). Data visualization literacy: Definitions, conceptual frameworks, exercises, and assessments. Proceedings of the National Academy of Sciences of the United States of America, 116(6), 1857-1864. https://doi.org/10.1073/pnas.1807180116

boyd, d., \& Crawford, K. (2012). Critical questions for Big Data. Information, Communication \& Society, 15(5), 662-679. https://doi.org/10.1080/1369118X.2012.678878

Bruner, J. (1991). The narrative construction of reality. Critical Inquiry, 18(1), 1-21. https://doi.org/10.1086/448619

Burton, L. (1984). Mathematical thinking: The struggle for meaning. Journal for Research in Mathematics Education, 15(1), 35-49. https://www.jstor.org/stable/748986

Calarco, J.M., Anderson, E., Meanwell, E. \& Knopf, A. (2020) 'Let's Not Pretend It's Fun': A mixed-methods analysis of increased time with children and mothers' well-being during the COVID-19 pandemic. (Working Paper). Accessed at https://osf.io/preprints/socarxiv/jyvk4/

Cardinal, J. (2020, May 13). Differing reports reveal data gap in COVID-19 case counts for Indigenous people in Canada. The Star. https:/www.thestar.com/news/canada/2020/05/13/differing-reports-reveal-data-gap-incovid-19-case-counts-for-indigenous-people-in-canada.html

Chronaki, A. (2011). Troubling essentialist identities: Performative mathematics and the politics of possibility. In M. Kontopodis, C. Wulf, \& B. Fichtner (Eds.), Children, development and education: Cultural, historical and anthropological perspectives (pp. 207-227). Springer.

Chronaki, A., \& Planas, N. (2018). Language diversity in mathematics education research: A move from language as representation to politics of representation. ZDM-Mathematics Education, 50, 1101-1111. https://doi.org/10.1007/s11858-018-0942-4

Chuang. (2020). Social contagion: Microbiological class war in China. Retrieved May 13, 2020, from http:// chuangcn.org/2020/02/socialcontagion/

Coburn, C. E. (2006). Framing the problem of reading instruction: Using frame analysis to uncover the microprocesses of policy implementation. American Educational Research Journal, 43(3), 343-379. https://doi.org/10.3102/00028312043003343

Cohn, N., Katz, J., Sanger-Katz, M., \& Quealy, K. (2020, March 27). Four ways to measure coronavirus outbreaks in US metro areas. The New York Times. https://www.nytimes.com/interactive/2020/03/27/upshot/ coronavirus-new-york-comparison.html

Curcio, F. (1987). Comprehension of mathematical relationships expressed in graphs. Journal for Research in Mathematics Education, 18, 382-393 https://www.jstor.org/stable/749086

Diakopoulos, N., \& Hullman, J. (2011). Visualization rhetoric: Framing effects in narrative visualization. IEEE Transactions on Visualization and Computer Graphics, 17(12), 2231-2240. https://oi.org/10.1109/TVCG.2011.255

D’Ignazio, C., \& Klein, L. (2020). Data feminism. MIT Press.

Dourish, P., \& Gómez Cruz, E. (2018). Datafication and data fiction: Narrating data and narrating with data. Big Data \& Society, 5(2), 1-10. https://doi.org/10.1177/2053951718784083

Duval, R. (2006). A cognitive analysis of problems of comprehension in a learning of mathematics. Educational Studies in Mathematics, 61(1-2), 103-131. https://doi.org/10.1007/s10649-006-0400-z

Entman, R.M. (2007). Framing bias:Media in the distribution of power. Journal of Communication, 57(1), 163173. https://doi.org/10.1111/j.1460-2466.2006.00336.x

Ewing, J. (2011). Mathematical intimidation: Driven by the data. Notices of the American Mathematical Society, $58(5), 667-673$

Frankenstein, M. (2012). Beyond math content and process: Proposals for underlying aspects of social justice education. In A. Wager \& D. Stinson (Eds.), Teaching mathematics for social justice: Conversations with educators (pp. 49-62). National Council of Teachers of Mathematics.

Friel, S. N., Curcio, F. R., \& Bright, G. W. (2001). Making sense of graphs: Critical factors influencing comprehension and instructional implications. Journal for Research in Mathematics Education, 32(2), 124-158. https://doi.org/10.2307/749671 
Gabrys, J., Pritchard, H., \& Barratt, B. (2016). Just good enough data: Figuring data citizenships through air pollution sensing and data stories. Big Data \& Society, 3(2), 1-14. https://doi.org/10.1177/2053951716679677

Gal, I. (2002). Adult statistical literacy: Meanings, components, responsibilities. International Statistical Review, $70(1), 1-25$.

Galesic, M., \& Garcia-Retamero, R. (2011). Graph literacy: A cross-cultural comparison. Journal of Medical Decision Making, 31(3), 444 457. https://doi.org/10.1177/0272989X10373805

Glazer, N. (2011). Challenges with graph interpretation: A review of the literature. Studies in Science Education, 47(2), 183-210. https://doi.org/10.1080/03057267.2011.605307

Gutstein, E. (2006). Reading and writing the world with mathematics: Toward a pedagogy for social justice. Routledge.

Hall, S. (1997). Representation: Cultural representations and signifying practices. SAGE.

Hall, J., \& Barwell, R. (2015). The mathematical formatting of obesity. In S. Mukhopadhyay \& B. Greer (Eds.), Proceedings of the Eighth International Mathematics Education and Society Conference (pp. 557-570). https://www.mescommunity.info/MES8ProceedingsVol3.pdf

Honnor, P. (2020, April 2). 7 ways to explore the math of the coronavirus using the New York Times. The New York Times. Retrieved April 5, 2020, from https://www.nytimes.com/2020/04/02/learning/7-ways-toexplore-the-math-of-the-coronavirus-using-the-new-york-times.html

Israel Ministry of Health. (2020). Patient No. 16 is a bus driver from Jerusalem who accompanied the Greek Pilgrim group. Retrieved April 2, 2020, from https://www.health.gov.il/English/News_and_Events/ Spokespersons_Messages/Pages/06032020_1.aspx

Katz, J., \& Sanger-Katz, M. (2020, May 26). Coronavirus deaths by US state and country over time: Daily tracker. The New York Times. Retrieved April 2, 2020, from https://www.nytimes.com/interactive/2020/03/ 21/upshot/coronavirus-deaths-by-country.html

Kristof, N., \& Thompson, S. (2020, March 25). Trump wants to 'Reopen America': Here's what happens if we do. The New York Times. Retrieved April 2, 2020, from https://www.nytimes.com/interactive/2020/03/25/ opinion/coronavirus-trump-reopen-america.html

Latour, B. (1984/1988). The pasteurization of France. Harvard University Press (translated by Alan Sheridan and John Law).

Lee, S., Kim, S. H., Hung, Y. H., Lam, H., Kang, Y. A., \& Yi, J. S. (2016). How do people make sense of unfamiliar visualizations?: A grounded model of novice's information visualization sensemaking. IEEE Transactions on Visualization and Computer Graphics, 22(1), 499-508. https://doi.org/10.1109/TVCG.2015.2467195

Lem, S., Onghena, P., Verschaffel, L., \& van Dooren, W. (2013). The heuristic interpretation of box plots. Learning and Instruction, 26, 22-35. https://doi.org/10.1016/j.learninstruc.2013.01.001

Loukissas, Y. A. (2019). All data are local: Thinking critically in a data-driven society. MIT Press.

Lukawiecki, J. (2018). Reconciling promises and reality: Clean drinking water for First Nations. David Suzuki Foundation https://davidsuzuki.org/science-learning-centre-article/reconciling-promises-and-reality-cleandrinking-water-for-first-nations/

Meaney, T. (2013). The privileging of English in mathematics education research, just a necessary evil? In M. Berger, K. Brodie, V. Frith, \& K. le Roux (Eds.), Proceedings of the seventh international mathematics education and society conference (pp. 65-84). Mathematics Education and Society.

Neale, S. (1980). Genre. British Film Institute.

Onuoha, M. (n.d.) Missing-datasets. https://github.com/MimiOnuoha/missing-datasets

Peirce, C. S. (1905/1998). What pragmatism is. In The Peirce Edition Project (Ed.), The essential Peirce: Selected philosophical writings (vol. 2, pp. 331-345). Indiana University Press.

Phakeng, M. S. (2017). Visible and invisible diversity in academic publishing. For the Learning of Mathematics, $37(1), 19-20$.

Romano, A., Sotis, C., Dominioni, G., \& Guidi, S. (2020). The scale of COVID-19 graphs affects understanding, attitude, and policy preferences. Health Economics, 29, 1482-1949. https://doi.org/10.1002/hec.4143

Rotem, S., \& Ayalon, A. (2021). Exploring Israeli high-school graduates' explanations for the spread of the Coronavirus. Educational Studies in Mathematics. Advanced online publication. https://oi.org/10.1007/s10649-021-10042-3

Roth, W.-M. (2002). Reading graphs: Contributions to an integrative concept of literacy. Journal of Curriculum Studies, 34(1), 1-24. https://doi.org/10.1080/00220270110068885

Scauso, M., Fitzgerald, G., Tickner, A., Chadha Behera, N., Pan, C., Shih, C., \& Shimizu, K. (2020). COVID-19, democracies, and (de)colonialities. Democratic Theory, 7(2), 82-93. https://doi.org/10.3167/dt.2020.070211

Segel, E., \& Heer, J. (2010). Narrative visualization: Telling stories with data. IEEE Transactions on Visualization and Computer Graphics, 16(6), 1139-1148. https://doi.org/10.1109/TVCG.2010.179

Shah, P., \& Hoeffner, J. (2002). Review of graph comprehension research: Implications for instruction. Educational Psychology Review, 14, 47-69. https://doi.org/10.1023/A:1013180410169 
Shaughnessy, J. M. (2007). Research on statistics learning and reasoning. In F. K. Lester (Ed.), Second handbook of research on mathematics teaching and learning (pp. 957-1009). National Council of Teachers of Mathematics.

Skovsmose, O. (1992). Democratic competence and reflective knowing in mathematics. For the Learning of Mathematics, 12(2), 2-11 https://www.jstor.org/stable/40248044

Skovsmose, O. (1994). Towards philosophy of critical mathematics education. Kluwer.

Skovsmose, O. (2012). Critical mathematics education: A dialogical journey. In A. Wager \& D. Stinson (Eds.), Teaching mathematics for social justice: Conversations with educators (pp. 35-47). National Council of Teachers of Mathematics.

Skovsmose, O. (2014). Critique as uncertainty. Information Age Publishing.

Skovsmose, O. (2018). Mathematization as social process. In S. Lerman (Ed.), Encyclopedia of mathematics education. Springer. https://doi.org/10.1007/978-3-319-77487-9_112-2

Skye, C. (2020). Colonialism and the curve: Indigenous communities and bad COVID data. Yellowhead Institute https://yellowheadinstitute.org/covid19/

Statistics Canada (2017). Aboriginal peoples in Canada: Key results from the 2016 census. https://www150. statcan.gc.ca/n1/daily-quotidien/171025/dq171025a-eng.htm

Ta Nea. (2020a). Coronavirus: The ninth patient is in serious condition: 52 of his fellow travelers are looking for him. https://www.tanea.gr/2020/03/04/greece/koronoios-stin-ellada-diasolinomenos-sto-nosokomeio-tispatras-o-enatos-asthenis/

Ta Nea. (2020b). Coronavirus: Extraordinary measures in Larissa - All popular markets are closing. Athens, Greece. https://www.tanea.gr/2020/04/10/greece/ektakta-metra-sti-larisa-oi-apofaseis-pou-elifthisan-ypotsiodra-kai-xardalia/

Todorov, T. (1977). The poetics of prose. Cornell University Press.

Tversky, A., \& Kahneman, D. (1981). The framing of decisions and the psychology of choice. Science, 211, 453-458. https://doi.org/10.1126/science.7455683

Watson, J. M. (1997). Assessing statistical thinking using the media. In I. Gal \& J. Garfield (Eds.), The assessment challenge in statistics education (pp. 107-121). International Statistical Institute/ IOS Press.

Watson, J. M., \& Moritz, J. (1999). The beginning of statistical inference: Comparing two data sets. Educational Studies in Mathematics, 37, 145-168.

Wu, J., Cai, W., Watkins, D., \& Glanz, J. (2020, March 22). How the virus got out. The New York Times. https:// www.nytimes.com/interactive/2020/03/22/world/coronavirus-spread.html

Publisher's note Springer Nature remains neutral with regard to jurisdictional claims in published maps and institutional affiliations.

\section{Affiliations}

\section{Laurie H. Rubel ${ }^{1} \cdot$ Cynthia Nicol $^{2} \cdot$ Anna Chronaki ${ }^{3,4}$}

Cynthia Nicol

cynthia.nicol@ubc.ca

Anna Chronaki

Anna.chronaki@mau.se

1 Department of Mathematics Education, University of Haifa, Haifa, Israel

2 Department of Curriculum and Pedagogy, University of British Columbia, Vancouver, Canada

3 University of Thessaly, Volos, Greece

4 Malmö University, Malmö, Sweden 